\title{
Diabetes in India: Measuring the dynamics of a public health catastrophe
}

\author{
Pranav Kumar Patnaik, Kamlesh K. Jain ${ }^{1}$, P. Chandra ${ }^{2}$, Jaya Pathak ${ }^{3}$, K. V. Raman ${ }^{4}$, Asha Shah ${ }^{5}$ \\ Joint Director NCD, Ministry of Health $\mathcal{E}$ Family Welfare, Odisha, ${ }^{1}$ Associate Professor, Pt. JNM Medical College, Raipur $\mathcal{E}$ State Nodal \\ Officer, Directorate of Health Services, Chhattisgarh, ${ }^{2}$ Deputy Director NPCDCS $\mathcal{E}$ State Nodal Officer, Directorate of Health Services, \\ Madhya Pradesh, ${ }^{3}$ Associate Professor of Medicine, SSG Medical College, Baroda, Gujarat, ${ }^{4}$ Director of Health $\mathcal{G}$ Family Welfare Services, \\ Government of Puducherry, Puducherry, ${ }^{5}$ Professor $\mathcal{E}$ HOD of Medicine, PG Director, B.J. Medical College, Ahmedabad, Gujarat, India
}

\section{A B S T RAC T}

Diabetes has emerged as a major concern in the Indian health-care setting but has been underrecognized as a significant challenge in the context of public health policy due to the necessity to handle acute health conditions. Trends obtained from national and regional surveys over time strongly point to the increasing diabetes burden. In addition, people with undiagnosed and prediabetes can aggravate the burden in the near future. Long-term concerns arise from the rapid transformations such as urbanization, rural-urban migration, and lifestyle changes happening across different populations of India. Attempts at creating a rational diabetes prevention and management policy are severely hindered by a lack of comprehensive, standardized data on diabetes prevalence, and trends in the evolution of the epidemic. The impact of diabetes is multifaceted, ranging from the clinical impact of higher secondary complications to personal, psychosocial, and financial effects on the individual which create a cycle of negative outcomes. Given the chronic nature of diabetes, the impact is likely to remain as a self-perpetuating burden on the health-care system. The magnitude, spread, and impact of the diabetes epidemic are substantial, and it has transitioned to being a pandemic with potentially catastrophic implications for the Indian Public Health System. It is therefore essential to create public health policy specific to diabetes care that is effective in reducing the multidimensional impact of diabetes catastrophe and prevent further multiplication of this pandemic.

Key words: Diabetes mellitus, epidemic, prevalence, public health

\section{INTRODUCTION}

With high rates of prevalence and a steadily increasing demographic burden, diabetes has emerged as a major noncommunicable disease (NCD) worldwide. The current prevalence of diabetes in India is 69.2 million and is expected to rise to 123.5 million ( $78.5 \%$ increase) by the year 2040, effectively rendering every fifth diabetic in the world to be an Indian. Number of Type

\begin{tabular}{|l|l|}
\hline \multicolumn{2}{|c|}{ Access this article online } \\
\hline Quick Response Code: & Website: \\
\hline & www.joshd.net \\
\hline & \\
\hline
\end{tabular}

1 diabetes patients $<15$ years of age has been 70,200 in India in 2015. ${ }^{[1]}$ Further, an estimated 36.5 million people suffering from impaired glucose tolerance (IGT) may add to the existing burden within the near future. Common risk factors of diabetes such as unhealthy diet, harmful use of alcohol, tobacco, raised blood sugar during pregnancy and cholesterol, insufficient physical activity, and obesity are progressively taking

\footnotetext{
This is an open access article distributed under the terms of the Creative Commons Attribution-NonCommercial-ShareAlike 3.0 License, which allows others to remix, tweak, and build upon the work non-commercially, as long as the author is credited and the new creations are licensed under the identical terms.
}

For reprints contact: reprints@medknow.com

How to cite this article: Patnaik PK, Jain KK, Chandra P, Pathak J, Raman KV, Shah A. Diabetes in India: Measuring the dynamics of a public health catastrophe. J Soc Health Diabetes 2016;4:77-84.

Corresponding Author: Dr. Kamlesh K. Jain, D K Hospital Campus, Raipur, Chhattisgarh, India. E-mail: dr.kamleshjain@gmail.com 
roots across different population groups, affecting the younger and previously "low-risk" groups for diabetes. In addition, the Asian Indian phenotype and lifestyle changes associated with urbanization and sedentary lifestyles contribute to the increasing diabetes burden in India. ${ }^{[2]}$

Diabetes presents major challenges to the patients, health systems, and national economies. Further, the impact of few modifiable risk factors of diabetes resulting in individual poverty and a burden to the economic development of the society is still underappreciated. However, the global response to this economic burden is not proportionate to the challenge. Therefore, an integration of ongoing public health policies, on existing knowledge of cost-effective and reliable solutions and continued efforts to better understand the scientific basis of the disease, is required to effectively fight diabetes. The current policy initiatives in India is hindered by (a) extrinsic factors - low focus on NCDs due to high priority required for "immediate" public health concerns like infectious diseases and (b) intrinsic factors - lack of accurate national-level data which sufficiently impacts public discourse on diabetes management. These limitations together seem that diabetes is an "affluent" disease, consigned to the second line of priorities in public health policies. Although numerous individual studies have established the overall magnitude of diabetes burden in India, current epidemiological data on socioeconomic and geographic variations are inadequate to create an informed and detailed discourse among policymakers. Further, awareness about the full impact of diabetes at an individual and health-care system level is also low. Cumulatively, the low awareness, burden, and policy inertia of diabetes results in a public health catastrophe of impending diabetes. The current review aims to present an overview of the epidemiological extent of diabetes, in terms of gross prevalence of diabetes and prediabetes, as well as undiagnosed, and urban-rural divide in the prevalence of diabetes. Further, the review seeks to demonstrate the multifaceted impact of diabetes on public health concerns in India both at individual and systemic level. Ultimately, the review seeks to give an overview of the diabetes pandemic, and its importance as a public health concern to enable policy makers to make informed policy decisions.

\section{CURRENT ESTIMATES OF PREVALENCE: DO WE KNOW ENOUgh ABOUT DiABETES PREVALENCE?}

The first nationwide study on the prevalence of Type 2 diabetes mellitus (T2DM) reported $2.1 \%$ and $1.5 \%$ prevalence in the urban and rural populations of India, respectively. Subsequent studies [Table 1$]^{[3-11]}$ have

\begin{tabular}{|c|c|c|c|c|}
\hline Year & Reference & Place & Sample & Prevalence (\%) \\
\hline 1999 & Ramankutty et al. & Kerala & - & 16.3 \\
\hline 2000 & Zargar et al. & Kashmir & 6091 & 6.1 \\
\hline \multirow[t]{6}{*}{2001} & Ramachandran et al. & New Delhi & 2300 & 10.3 \\
\hline & & Chennai & 1668 & 13.5 \\
\hline & & Hyderabad & 1427 & 16.6 \\
\hline & & Mumbai & 2084 & 9.3 \\
\hline & & Bengaluru & 1359 & 12.4 \\
\hline & & Kolkata & 2378 & 11.7 \\
\hline 2004 & Agrawal et al. & Rajasthan & 2099 & 1.8 \\
\hline 2006 & Deo et al. & Maharashtra & 1022 & 9.3 \\
\hline 2008 & Ramachandran et al. & Tamil Nadu & 2584 & 9.2 \\
\hline 2008 & Zargar et al. & Kashmir & 3032 & 2.5 \\
\hline 2009 & Vijayakumar et al. & Kerala & 1990 & 14.6 \\
\hline \multirow[t]{4}{*}{2011} & Anjana et al. & Maharashtra & 3569 & 8.4 \\
\hline & & Tamil Nadu & 3509 & 10.4 \\
\hline & & Jharkhand & 2891 & 5.3 \\
\hline & & Chandigarh & 839 & 13.6 \\
\hline
\end{tabular}

demonstrated not only a rising prevalence of diabetes but also a wide variation across different parts of India. The recent NCD risk factor surveillance (from five states), estimated self-reported diabetes in urban areas (7.3\%), peri-urban/slum (3.2\%), and rural areas (3.1\%). ${ }^{[12]}$ Few national level studies ${ }^{[3,4]}$ have broadly elucidated the geographic and historical trends in diabetes prevalence at a gross level. However, the difference in diabetes prevalence rates between the four regions of Indian Council of Medical Research-INdia DIABetes (ICMR-INDIAB) Phase-I study could be indicative of infrastructural issues: Conducting the study in government health-care facilities, accessibility and availability of diagnostic tools and trained personnel at such facilities, differences in diabetes unawareness impeding healthcare-seeking behavior (thereby under-representing diabetes patients in primary sampling units) in some regions or unwillingness to seek healthcare due to familial and social reason, etc., Thus, while national level studies provide a strong basis to infer historical changes in prevalence and indicate an overview of disease prevalence, the utility of current data in policymaking decisions is limited due to lack of data on infrastructure, lifestyle, and localization factors.

Epidemiological studies on specific population from Chennai (Chennai Urban Rural Epidemiology Study) also support the estimates of rising prevalence of diabetes in India. With repeated epidemiological studies (over two decades) and analysis of historical changes in prevalence trends of diabetes and associated complications, a diabetes registry specific to this population could be developed. ${ }^{[13]}$ However, it appears that combining data from few studies on dynamics of diabetes conducted on "national" and "specific" population sizes cannot provide a comprehensive overview to frame the diabetes policy for the nation due to huge variations 
in the factors discussed above. Comprehensive databases like disease registries are valuable sources of data for the description of temporal trends in prevalence, development, and mortality of a disease. Such registries already exist for chronic kidney disease ${ }^{[14]}$ and coronary heart disease ${ }^{[15]}$ in India and must be considered essential for providing a comprehensive overview of diabetes as well. ${ }^{[16]}$ The quality of any disease registry depends largely on the quality of input data and processes involved in updating it and keeping its integrity. In resource-limited settings, the participation of various stakeholders (such as public and private health-care providers, specialists, and nongovernmental organizations) to create usable databases on diabetes prevalence both at gross and grassroots levels is essential in developing data for policy-making decisions. Although the main characteristic in the evolution of diabetes catastrophe in India is the estimates of huge diabetes burden, it is limited by a lack of appropriate data from current studies and may be underestimating the actual burden. Trends in prevalence rates reveal that the current estimates are likely to escalate in the near future with the addition of previously undiagnosed diabetes cases and proliferation of diabetes risk factors.

\section{The Real Magnitude of the Diabetes CATASTROPHE}

In addition to available data on huge prevalence of diabetes that is spreading at an alarming rate, the inclusion of undiagnosed and prediabetes cases and addition of new cases due to massive socioeconomic changes (urbanization, disappearance of traditional lifestyles) can worsen the scenario and increase the current estimates of actual burden. This might be due to the fact that in terms of sheer numerical presence, diabetes has ceased to be an epidemic and has transitioned to being a public health catastrophe.

\section{Undiagnosed diabetes: The hidden danger}

Patients who are unaware of their diabetes status are described as having undiagnosed diabetes. The International Diabetes Federation (IDF) estimated that there were approximately 36 million adults with undiagnosed diabetes in India in 2015 (IDF 2015). A very high prevalence of undiagnosed diabetes in the community has been reported by studies that have shown an increase in the prevalence of diabetes [Table 2] ${ }^{[14]}$ Due to late diagnosis/nondiagnosis of diabetes, patients face a considerable burden of diabetes and its complications. This can be exemplified by high baseline (mean) glycated hemoglobin (HbA1c, 9.2\%) reported in a large observational study (A1chieve) on Indian patients ( $n$ $=20,554)$ with T2DM. ${ }^{[17]}$ Patients with undiagnosed diabetes represent an unidentified "set of patients," whose nonrepresentation in prevalence estimates, may lead to the formulation of insufficient or inappropriate policy initiatives, and may escalate future treatment costs. This could in turn lead to indirect economic loss owing to loss of productivity due to diabetes (previously unidentified) and escalation of health-care costs associated with the management of more severe diabetes.

\section{Prediabetes: Familiar threat}

IGT and impaired fasting glucose are collectively called as prediabetic states. Prediabetes represents an intermediate state of abnormal glucose regulation that exists between normal glucose homeostasis and diabetes. ${ }^{[18]}$ Unlike undiagnosed diabetes, prediabetes represents a "set of patients" with an identified propensity to develop diabetes which will further accelerate the spread of diabetes in the future. In four out of six cities studied in the NUDS study, the prevalence of IGT was higher than that of T2DM. ${ }^{[3]}$ It is noteworthy that in the ICMR-INDIAB study, Jharkhand which had a diabetes prevalence of only $3 \%$ showed a prediabetes prevalence of $8.3 \%(\sim 3$ times higher). ${ }^{[4]}$ Using prediabetes as an index, the worsening of (existing) diabetes burden can be accurately anticipated and appropriate policy measures formulated. However, till date, there have been very limited studies reporting the prevalence of prediabetes. As per IDF estimates, India tops the list with 36.5 million adults with IGT, in 2015, which is expected to rise to 63.6 million by $2040 .^{[1]}$ The lack of specific data about prediabetes in India ${ }^{[19]}$ represents not only an aggravated diabetes burden in the future but also a lost opportunity to manage the condition before it manifests into frank diabetes.

\begin{tabular}{|c|c|c|c|c|c|c|c|c|c|c|c|c|}
\hline \multirow[t]{2}{*}{ Status } & \multicolumn{3}{|c|}{ Tamil Nadu } & \multicolumn{3}{|c|}{ Maharashtra } & \multicolumn{3}{|c|}{ Jharkhand } & \multicolumn{3}{|c|}{ Chandigarh } \\
\hline & Urban & Rural & Overall & Urban & Rural & Overall & Urban & Rural & Overall & Urban & Rural & Overall \\
\hline Total number & 1029 & 2480 & 3509 & 1093 & 2476 & 3569 & 840 & 2051 & 2891 & 839 & 2247 & 3086 \\
\hline KD (\%) & 8.5 & 4.1 & 6 & $3.7^{\star}$ & 1.7 & 2.5 & $8.4^{*}$ & 0.7 & 2.4 & $6.6^{*}$ & 3.1 & 6.2 \\
\hline NDD (\%) & $5.2^{*}$ & 3.8 & 4.4 & $7.2^{*}$ & 4.9 & 5.9 & $5.1^{\star}$ & 2.3 & 2.9 & 7.6 & 5.2 & 7.4 \\
\hline Ratio of KD: NDD & $01: 00.6$ & 01:00.9 & $01: 00.7$ & 01:01.9 & $01: 02.9$ & $01: 02.4$ & 01:00.6 & $01: 03.3$ & 01:01.2 & 01:01.2 & 01:01.7 & 01:01.2 \\
\hline $\begin{array}{l}\text { Total } \\
\text { diabetes (\%) }\end{array}$ & $13.7^{\star}$ & 7.8 & 10.4 & $10.9^{*}$ & 6.5 & 8.4 & $13.5^{\star}$ & 3 & 5.3 & $14.2^{\star}$ & 8.3 & 13.6 \\
\hline Prediabetes (\%) & $9.8^{*}$ & 7.1 & 8.3 & $15.2^{*}$ & 11.1 & 12.8 & $10.7^{*}$ & 7.4 & 8.1 & 14.5 & 14.7 & 14.6 \\
\hline
\end{tabular}




\section{Rising urbanization: Inevitable lifestyle changes}

The trend of greater diabetes prevalence in the urban population is amply clear from existing data. ${ }^{[20,21]}$ Further, rural populations are also undergoing dynamic changes in their dietary patterns and lifestyle. ${ }^{[22-24]}$ Therefore, it is essential to consider the long-term implications of these changes while framing the diabetes policies. Urbanization, both in terms of emergence of new urban centers and rural migration to existing urban centers (pubs.org), may cause lifestyle changes, and comparable diabetes prevalence rates between urban vs. migrant populations $(13.5 \%$ and $14.3 \%$, respectively). ${ }^{[25]}$ This might be due to the newly adopted lifestyle of migrants that put them at similar risk of diabetes to that of the urban population. In addition, "epidemiological transition," due to improved access to quality healthcare, consumption of junk food, control of communicable diseases, and increased longevity in life ${ }^{[26]}$ may expose the previously low-risk populations to high-risk lifestyle patterns and result in a rapid rise in diabetes. ${ }^{[12]}$

The combination reveals a wider diabetes burden than currently perceived, and worsens the situation with the addition of large "sets of patients" with undiagnosed and prediabetes conditions. Precisely, in quantitative terms, the spread and magnitude of diabetes in India more correctly represent a catastrophic pandemic than an epidemic and are amplified by its qualitative impact on patients and health-care system. Formulating public health policies based on existing knowledge on gross prevalence rates of diabetes may not effectively manage the pandemic and require periodic improvements.

\section{The Multifaceted Impact of the DIABETES}

The dimensions of the diabetes catastrophe cannot be measured purely in numeric terms of prevalence and incidence. Diabetes has a multifaceted impact on patients and causes greater public health concerns due to its impact on clinical, financial, psycho-social, and personal aspects on the affected populations. While the prevalence numbers narrate the story of the scale and spread of the problem, its qualitative impact can only be understood in terms of its effects on the individual and the health-care system. The negative effects of financial, clinical, and psychosocial effects contribute to each other and aggravate diabetes burden.

\section{Clinical impact}

"Successful" diabetes management involves initiating early therapeutic interventions to maintain healthy glycemic levels and minimize the secondary complications in the long term. However, such interventions are limited by a range of systemic factors: (a) Nonawareness of diabetes leading to delayed diagnosis and difficulty in timely management, ${ }^{[27]}$ (b) lack of focus on diabetes care in PHCs, resulting in suboptimal management of known cases, ${ }^{[28]}$ and (c) development of secondary complications even with short period of dysregulated metabolic status. ${ }^{[29]}$ Further, in the Indian health-care conditions, diabetes management is often neglected due to the higher priority to manage acute health conditions. Suboptimally managed diabetes leads to a significant clinical impact in the development of systemic secondary complications. Studies have shown that clinical impact of diabetes can be reduced by glycemic control; a $1 \%$ decrease in $\mathrm{HbA} 1 \mathrm{c}$ can reduce the risk of diabetes-related deaths by $21 \%$, microvascular complications by $37 \%$, and myocardial infarction by $14 \% .{ }^{[30]}$ The relevance of such facts and figures in the Indian Public Health context may not be clear. However, given the clinical impact of the huge burden of diabetes on public health, there is a clear need to assess the magnitude and importance of such strategy (reducing the clinical impact) in making policy decisions. The present lack of clear diabetes management policy in India cannot be accepted due to lack of appropriate information or scale of resources for management. National and international guidelines recommend simple, cost-effective methods such as diet and lifestyle modification, and well-understood escalation of therapeutic interventions as an early management strategies to effectively manage diabetes. ${ }^{[31]}$

\section{Financial impact}

The financial burden of diabetes is one of the readily identifiable dimensions of the diabetes catastrophe. The chronic nature of the disease and its associated complications increase the cost of diabetes treatment. Estimates report that direct costs, rather than indirect costs form the largest proportions of the total annual cost of diabetes. ${ }^{[32]}$ In addition to the high direct costs for ambulatory care of diabetes in India, ${ }^{[33]}$ costs of inpatient care also increases with each increase in the number of secondary complications than the costs for no complications. ${ }^{[34]}$ Therefore, if left untreated, the financial burden of diabetes can become unmanageably high.

These data on the financial burden of diabetes management, while significant, must be understood both in terms of the possible impact on the individual and the health-care system. In terms of an individual patient suffering from diabetes, the financial burden consumes a considerable part of earnings (months of salary for the management of a simple ulcer) and poses the financial impact of disability (lost wages for simple tumor and disability for amputation). ${ }^{[35]}$ This causes a rapid increase in the financial burden of an 
individual leading to out-of-pocket expenditure for medical needs, which is a common phenomenon in India. ${ }^{[36]}$ At a systemic level, inability to respond to diabetes at an appropriate time will mean the same level of financial burden on the health-care system as a whole but on a massive scale due to the progressively increasing numbers of patients facing the situation. In addition, the loss of productivity and indirect effects of disability and sickness exacerbate the overall loss to the society as a whole. ${ }^{[37]}$

This financial burden adds to the economic burden of lost employment due to disease and the clinical burden of aggravated disease. In terms of economic burden, compared to other countries, patients from India have to forego earnings from more number of days for the management of diabetic foot ulcers. ${ }^{[35]}$ This might be due to differing plans of therapy, nonuniform support from government and insurance, and varied costs of drugs and devices in the individual country. Further, the WHO estimates higher economic burden for a low-income family from India (with an adult diabetes patient) compared to a family in the USA (with a child who has diabetes). ${ }^{[38]}$ The DEDICOM survey also reports that direct costs of ambulatory care are disproportionately high in the lower income groups. ${ }^{[33]}$ Therefore, the rationale for formulating effective diabetes management policies in India is both pragmatic and ethical.

\section{Psychosocial and personal impact}

The emotional and psychological needs of people living with diabetes are complex. The psychosocial impact is an unseen and often neglected aspect of diabetes which has an important effect on treatment outcomes and individual well-being. Indian patients with diabetes have one of the lowest levels of psychological well-being, higher perception of diabetes-associated social and personal distress, ${ }^{[39]}$ and the depression (in one in four patients). ${ }^{[40]}$ Right from the diagnosis of diabetes, patients reported increased stress and anxiety, as well as decreased quality of life. . $^{[41]}$ The stress and anxiety associated with not fulfilling the familial responsibilities causes feeling of "shame," "guilt," and "self-worth" in patients, ${ }^{[42]}$ impacting their social functioning, and interpersonal, as well as intra-familial relationships.

Although quantifying the psychosocial impact of diabetes on the overall disease burden is rare, the qualitative impact on individual patient and society is clear. At an individual level, the impact of psychosocial stress along with socioeconomic differences can be worsening. It is reported that diabetes-associated depression and co-distress are most common among patients in the poorest income group than the middle- and high-income groups, ${ }^{[41-42]}$ which might delay their diabetes care and develop secondary complications, affecting a vicious cycle of negative effects. In addition to the high self-blame by patients, societal perception of holding the individual "responsible" for the "lifestyle disease," aggravates the impact and may lead to discrimination because of their diabetes. A higher than the average perception rate of "being discriminated because of diabetes" was reported by patients with diabetes from India (next only to Turkey) in the multinational DAWN study. ${ }^{[43]}$ Such discrimination in historically neglected patients with diabetes could be a trigger for more widespread damage due to a range of already existing risk factors for depression and diabetes, such as poor metabolic control, higher complication rates, increased health-care costs, lost productivity, and lower quality of life, as well as increased risk of death. ${ }^{[44]}$

The huge prevalence of diabetes in India impacts the financial, clinical, and psychosocial well-being of both individual and health-care system as a whole. It is established that optimal management can reduce the clinical impact of diabetes and avoid the burden of long-term secondary complications. However, inertia in formulating appropriate management policies, due to the perceived unimportance of related issues, causes suboptimal diabetes management and aggravates an important dimension of this catastrophe, the clinical impact. The financial aspect causes a significant burden to the individual and may also restrict the use of future financial resources to feed the recurring costs of management over a long period of time. Further, the impact of diabetes on psychological stressors is manifested at an individual level and community/societal level as discrimination against diabetes. Therefore, to improve psychosocial comfort and reduce the widespread negative perceptions of diabetes in Indian patients, it is essential not only to provide optimal long-term management but also provide diabetes education, counseling, and awareness as an integral part of management policy/program. Thus, the triumvirate of disease prevalence, disease impact, and policy inertia together make diabetes an impending "catastrophe" for the Indian Public Healthcare Setting.

\section{The Diabetes Catastrophe and Policy IMPLICATIONS}

The multifaceted impact of diabetes on individuals and the society amply justifies the need for a comprehensive diabetes management policy and points to the necessary components of such a policy. Policymakers should view diabetes management as a poverty reduction strategy due to the large and long-term benefits that are likely to be accumulated, both at the individual and system-level. 
Such policies, though complementary to the measures taken to manage acute conditions in achieving overall public health, should not be considered competitive in terms of public health. Diabetes shares several risk factors with other diseases ${ }^{[45]}$ and includes complex socioeconomic changes as well. ${ }^{[46]}$ Hence, strategies to prevent multiple diabetes risk factors must not only attempt to reduce the individual risk factors across the whole population but also simultaneously deal with multiple risk factors. ${ }^{[4]]}$

Public health intervention policies focused on long-term primary prevention strategies, such as promoting healthy lifestyle and spreading disease awareness through public education, can reduce the risk of diabetes and other NCDs in the community. Such policies can be complemented by proactive changes promoting healthy lifestyle patterns (ensuring availability of high-fiber, low-fat foodstuffs, and healthy mid-day school meals $)^{[48]}$ and discouraging unhealthy patterns (high tax on tobacco, alcohol, sugary drinks, etc.). ${ }^{[49]}$ Public health policies with a "life course approach" which starts with maternal health, prenatal nutrition, and pregnancy outcomes can be more effective in the management of diabetes and other NCDs. Other components include proper feeding practices in infancy and childhood, adolescent health through reaching children at school and youngsters at college, interventions targeting adults to encourage healthy lifestyle patterns, and discourage unhealthy patterns from youth into old age, and providing cost-effective and quality diabetes care to the needful. Public health principles as outlined in the Toronto Charter for Physical Activity outline the possibility of using mass media in creating awareness about the need to make healthy lifestyle changes for alleviating the diabetic burden in the country. ${ }^{[50]}$

Public health-care policies in India were previously successful in tackling communicable diseases: Universal DOTS coverage for tuberculosis through pharmaceutical interventions ${ }^{[51]}$ and massive awareness campaigns accompanying the pulse polio campaigns. ${ }^{[52]}$ Similarly, diabetes-specific policies using currently available networks and resources can be implemented nation-wide; optimization of policy implementation is the key to such strategies. In Tamil Nadu State, government-funded state-wide adult NCD risk profiling (for age above 30 years) is done using a risk scoring system (ENN score) by village volunteers; those at risk ( $<30$ score) are advised to attend the village level screening camps for disease diagnosis. Identified cases are entered into a Primary Healthcare Centre-based registry and are managed further as per protocols. ${ }^{[53]}$ The Tamil Nadu model reveals the reach of public healthcare up to the village level and resource planning in developing a diabetes-specific registry and providing care facilities. Thus, existing infrastructure and resources across the country can be optimized to create channels for providing quality diabetes care to patients already affected by diabetes. In continuation, improving the reach of public and private primary health-care centers beyond the villages to more remote areas can further spread the awareness and improve the diagnosis of disease. In addition, upgrading the PHC infrastructures to manage cases of prediabetes can reduce the future burden of diabetes. Over time, such channels can become the foundation for further policy interventions (e.g. providing free/subsidized insulin, counseling about lifestyle interventions, etc.). Toward this goal, the Cabinet Committee of India on Health Approved the National Program for Prevention and Control of Cancer, Diabetes, Cardiovascular Diseases and Stroke in 2010. ${ }^{[54]}$ The main strategies under this program are the prevention of risk factors through behavior change communication, early diagnosis and treatment, capacity building of human resource, surveillance, monitoring, and evaluation.

\section{CONCLUSION}

The emergence of diabetes as a major concern on the Indian Public Health Perspective is not accompanied by vigorous efforts to control and contain the problem, and the extent of the problem is not entirely appreciated in the realm of public health policy making. Public policy is currently focused on immediate concerns presented by acute and infectious diseases. A proper understanding of the dynamics of diabetes suggests that the disease has transitioned from being an epidemic of concern to pandemic, with the potential to cause catastrophic consequences for the Indian Public Healthcare Setting. There are three clear indications in support of such an assertion. First, the current evidence clearly demonstrates a widespread and huge burden of diabetes across the country, and this evidence can be used in formulating sound diabetes management policies. Second, due to the demographic changes in the society, large numbers of undiagnosed and prediabetes cases, and previously low-risk populations (like rural populations, young people) are likely to add to the future burden of diabetes. Thus, the currently observable burden is likely to be only a small proportion of the overall burden that is likely to manifest in the future. Third, the impact of diabetes on individuals and the health-care system is multidimensional. The current policy inertia in formulating a response to the diabetes pandemic causes a high clinical impact of diabetes, which in turn leads to greater financial and psychosocial impact. 
In conjunction with each other, these aspects of diabetes impact affect the personal and social functioning of individuals and emerge as a major challenge to the public health-care system. Integrating diabetes and other NCDs in health management information systems (HMIS) can provide valuable information like disease burden status and help in better planning for future. This aggravation of the magnitude, spread and impact of the diabetes pandemic is likely to overburden the health-care systems and is apt to be labeled a "public health catastrophe." It is therefore essential to initiate swift and broad response with a long-term vision to contain the pandemic. The policy makers in India have to understand the gravity of diabetes burden and formulate specific health-care policies that address the various dimensions of diabetes catastrophe.

\section{Acknowledgments}

The authors thank Jeevan Scientific Technology Limited, Hyderabad, India for providing medical writing assistance in the development of this manuscript.

\section{Financial support and sponsorship}

Nil.

\section{Conflicts of interest}

There are no conflicts of interest.

\section{REFERENCES}

1. International Diabetes Federation. Diabetes Atlas. $7^{\text {th }}$ ed. Odisha: International Diabetes Federation; 2015.

2. Mohan V, Sandeep S, Deepa R, Shah B, Varghese C. Epidemiology of type 2 diabetes: Indian scenario. Indian J Med Res 2007;125:217-30.

3. Ramachandran A, Snehalatha C, Kapur A, Vijay V, Mohan V, Das AK, et al. High prevalence of diabetes and impaired glucose tolerance in India: National Urban Diabetes Survey. Diabetologia 2001;44:1094-101.

4. Anjana RM, Pradeepa R, Deepa M, Datta M, Sudha V, Unnikrishnan $\mathrm{R}$, et al. Prevalence of diabetes and prediabetes (impaired fasting glucose and/or impaired glucose tolerance) in urban and rural India: Phase I results of the Indian Council of Medical Research-INdia DIABetes (ICMR-INDIAB) study. Diabetologia 2011;54:3022-7.

5. Raman Kutty V, Joseph A, Soman CR. High prevalence of type 2 diabetes in an urban settlement in Kerala, India. Ethn Health 1999;4:231-9.

6. Zargar AH, Khan AK, Masoodi SR, Laway BA, Wani AI, Bashir MI, et al. Prevalence of type 2 diabetes mellitus and impaired glucose tolerance in the Kashmir Valley of the Indian subcontinent. Diabetes Res Clin Pract 2000;47:135-46.

7. Agrawal RP, Singh G, Nayak KC, Kochar KD, Sharma RC, Beniwal $R$, et al. Prevalence of diabetes in camel-milk consuming 'RAICA' rural community of North-West Rajasthan. Int J Diabetes Dev Ctries 2004;24:109-14.

8. Deo SS, Zantye A, Mokal R, Mithbawkar S, Rane S, Thakur K. To identify the risk factors for high prevalence of diabetes and impaired glucose tolerance in Indian rural population. Int $\mathrm{J}$ Diabetes Dev Ctries 2006;26:19-23.

9. Ramachandran A, Mary S, Sathish CK, Selvam S, Catherin Seeli A, Muruganandam M, et al. Population based study of quality of diabetes care in Southern India. J Assoc Physicians India 2008;56:513-6.

10. Zargar AH, Wani AA, Laway BA, Masoodi SR, Wani Al, Bashir MI, et al. Prevalence of diabetes mellitus and other abnormalities of glucose tolerance in young adults aged 20-40 years in North India (Kashmir Valley). Diabetes Res Clin Pract 2008;82:276-81.

11. Vijayakumar G, Arun R, Kutty VR. High prevalence of type 2 diabetes mellitus and other metabolic disorders in rural Central Kerala. J Assoc Physicians India 2009;57:563-7.

12. Mohan V, Mathur P, Deepa R, Deepa M, Shukla DK, Menon GR, et al. Urban rural differences in prevalence of self-reported diabetes in India - the WHO-ICMR Indian NCD risk factor surveillance. Diabetes Res Clin Pract 2008;80:159-68.

13. Mohan V, Deepa M, Deepa R, Shanthirani CS, Farooq S, Ganesan A, et al. Secular trends in the prevalence of diabetes and impaired glucose tolerance in urban South India - the Chennai Urban Rural Epidemiology Study (CURES-17). Diabetologia 2006;49:1175-8.

14. Pagidipati NJ, Huffman MD, Jeemon P, Gupta R, Negi $P$, Jaison $\mathrm{TM}$, et al. Association between gender, process of care measures, and outcomes in ACS in India: Results from the detection and management of coronary heart disease (DEMAT) registry. PLoS One 2013;8:e62061.

15. Rajapurkar MM, John GT, Kirpalani AL, Abraham G, Agarwal SK, Almeida AF, et al. What do we know about chronic kidney disease in India: First report of the Indian CKD registry. BMC Nephrol 2012;13:10.

16. Carstensen B, Borch-Johnsen K. Register-based studies of diabetes. Scand J Public Health 2011;39 7 Suppl: 175-9.

17. Mohan V, Shah S, Saboo B. Current glycemic status and diabetes related complications among type 2 diabetes patients in India: Data from the A1chieve study. J Assoc Physicians India 2013;61 1 Suppl:12-5.

18. Nathan DM, Davidson MB, DeFronzo RA, Heine RJ, Henry RR, Pratley R, et al. Impaired fasting glucose and impaired glucose tolerance: Implications for care. Diabetes Care 2007;30:753-9.

19. Raghupathy P, Antonisamy B, Fall CH, Geethanjali FS, Leary SD, Saperia J, et al. High prevalence of glucose intolerance even among young adults in south India. Diabetes Res Clin Pract 2007;77:269-79.

20. Chow CK, Raju PK, Raju R, Reddy KS, Cardona M, Celermajer DS, et al. The prevalence and management of diabetes in rural India. Diabetes Care 2006;29:1717-8.

21. Sadikot SM, NigamA, Das S, Bajaj S, Zargar AH, Prasannakumar KM, et al. The burden of diabetes and impaired fasting glucose in India using the ADA 1997 criteria: Prevalence of diabetes in India study (PODIS). Diabetes Res Clin Pract 2004;66:293-300.

22. Yadav K, Krishnan A. Changing patterns of diet, physical activity and obesity among urban, rural and slum populations in North India. Obes Rev 2008;9:400-8.

23. Rao CR, Kamath VG, Shetty A, Kamath A. A cross-sectional analysis of obesity among a rural population in coastal Southern Karnataka, India. Australas Med J 2011;4:53-7.

24. Bhagyalaxmi A, Atul T, Shikha J. Prevalence of risk factors of non-communicable diseases in a District of Gujarat, India. J Health Popul Nutr 2013;31:78-85.

25. Ebrahim S, Kinra S, Bowen L, Andersen E, Ben-Shlomo Y, Lyngdoh $\mathrm{T}$, et al. The effect of rural-to-urban migration on obesity and diabetes in India: A cross-sectional study. PLoS Med 2010;7:e1000268.

26. Khan FS, Lotia-Farrukh I, Khan AJ, Siddiqui ST, Sajun SZ, Malik AA, 
Patnaik, et al.: Diabetes in India: A public health catastrophic

et al. The burden of non-communicable disease in transition communities in an Asian megacity: Baseline findings from a cohort study in Karachi, Pakistan. PLoS One 2013;8:e56008.

27. Joshi SR, Saboo B, Vadivale M, Dani SI, Mithal A, Kaul U, et al. Prevalence of diagnosed and undiagnosed diabetes and hypertension in India - results from the Screening India's Twin Epidemic (SITE) study. Diabetes Technol Ther 2012;14:8-15.

28. Moses CR, Seshiah V, Sahay BK, Kumar A, Asirvatham AJ, Balaji V, et al. Baseline results indicate poor glycemic control and delay in initiation and optimization of insulin therapy: Results from the improving management practices and clinical outcomes in type 2 diabetes study. Indian J Endocrinol Metab 2012;16 Suppl 2:S432-3.

29. Boutayeb A. The double burden of communicable and non-communicable diseases in developing countries. Trans $R$ Soc Trop Med Hyg 2006;100:191-9.

30. Stratton IM, Adler AI, Neil HA, Matthews DR, Manley SE, Cull CA, et al. Association of glycaemia with macrovascular and microvascular complications of type 2 diabetes (UKPDS 35): Prospective observational study. BMJ 2000;321:405-12.

31. Inzucchi SE, Bergenstal RM, Buse JB, Diamant M, Ferrannini E, Nauck M, et al. Management of hyperglycemia in type 2 diabetes: A patient-centered approach: Position statement of the American Diabetes Association (ADA) and the European Association for the Study of Diabetes (EASD). Diabetes Care 2012;35:1364-79.

32. Grover S, Avasthi A, Bhansali A, Chakrabarti S, Kulhara P. Cost of ambulatory care of diabetes mellitus: A study from North India. Postgrad Med J 2005;81:391-5.

33. Kumar A, Nagpal J, Bhartia A. Direct cost of ambulatory care of type 2 diabetes in the middle and high income group populace of Delhi: The DEDICOM survey. J Assoc Physicians India 2008;56:667-74.

34. Kumpatla S, Kothandan H, Tharkar S, Viswanathan V. The costs of treating long-term diabetic complications in a developing country: A study from India. J Assoc Physicians India 2013;61:102-9.

35. Cavanagh P, Attinger C, Abbas Z, Bal A, Rojas N, Xu ZR. Cost of treating diabetic foot ulcers in five different countries. Diabetes Metab Res Rev 2012;28 Suppl 1:107-11.

36. Xu K, Evans DB, Kawabata K, Zeramdini R, Klavus J, Murray CJ. Household catastrophic health expenditure: A multicountry analysis. Lancet 2003;362:111-7.

37. Ramachandran A, Ramachandran S, Snehalatha C, Augustine C, Murugesan N, Viswanathan V, et al. Increasing expenditure on health care incurred by diabetic subjects in a developing country: A study from India. Diabetes Care 2007;30:252-6.

38. Available from: http://www.who.int/mediacentre/factsheets/fs236/ en/. [Last accessed on 2014 Jun 05].

39. Peyrot M, Rubin RR, Lauritzen T, Snoek FJ, Matthews DR, Skovlund SE. Psychosocial problems and barriers to improved diabetes management: Results of the Cross-National Diabetes Attitudes, Wishes and Needs (DAWN) Study. Diabet Med 2005;22:1379-85.

40. Poongothai S, Anjana RM, Pradeepa R, Ganesan A, Unnikrishnan R, Rema M, et al. Association of depression with complications of type 2 diabetes - the Chennai Urban Rural Epidemiology Study (CURES- 102). J Assoc Physicians India 2011;59:644-8.

41. Mendenhall E, Shivashankar R, Tandon N, Ali MK, Narayan KM, Prabhakaran D. Stress and diabetes in socioeconomic context: A qualitative study of urban Indians. Soc Sci Med 2012;75:2522-9.

42. Mendenhall E, Narayanan G, Prabhakaran D. Depression and diabetes in India: Perspectives and recommendations. Diabet Med 2012;29:e308-11.

43. Nicolucci A, Kovacs Burns K, Holt RI, Comaschi M, Hermanns N, Ishii $\mathrm{H}$, et al. Diabetes attitudes, wishes and needs second study (DAWN2 ${ }^{\mathrm{TM}}$ ): Cross-national benchmarking of diabetes-related psychosocial outcomes for people with diabetes. Diabet Med 2013;30:767-77.

44. Bajaj S, Jawad F, Islam N, Mahtab H, Bhattarai J, Shrestha D, et al. South Asian women with diabetes: Psychosocial challenges and management: Consensus statement. Indian J Endocrinol Metab 2013;17:548-62.

45. Deepa M, Pradeepa R, Anjana R, Mohan V. Noncommunicable diseases risk factor surveillance: Experience and challenge from India. Indian J Community Med 2011;36 Suppl 1:S50-6.

46. Corsi DJ, Subramanian SV. Association between socioeconomic status and self-reported diabetes in India: A cross-sectional multilevel analysis. BMJ Open 2012;2. pii: e000895.

47. Rose G. Sick individuals and sick populations 1985. Bull World Health Organ 2001;79:990-6.

48. Sathish T, Williams ED, Pasricha N, Absetz P, Lorgelly P, Wolfe R, et al. Cluster randomised controlled trial of a peer-led lifestyle intervention program: Study protocol for the Kerala diabetes prevention program. BMC Public Health 2013;13:1035.

49. Basu S, Vellakkal S, Agrawal S, Stuckler D, Popkin B, Ebrahim S. Averting obesity and type 2 diabetes in India through sugar-sweetened beverage taxation: An economic-epidemiologic modeling study. PLoS Med 2014;11:e1001582.

50. Abdullah B, Wolbring G. Analysis of newspaper coverage of active aging through the lens of the 2002 World Health Organization Active Ageing Report: A Policy Framework and the 2010 Toronto Charter for Physical Activity: A Global Call for Action. Int J Environ Res Public Health 2013;10:6799-819.

51. Chauhan LS, Tonsing J. Revised national TB control programme in India. Tuberculosis (Edinb) 2005;85:271-6.

52. John TJ, Vashishtha VM. Eradicating poliomyelitis: India's journey from hyperendemic to polio-free status. Indian $\mathrm{J}$ Med Res 2013;137:881-94.

53. Nalamana Tamizhagam. National Rural Health Mission. State Health Society. Tamil Nadu. Government of Tamil Nadu's Diabetes and Hypertension Prevention Initiative. Available from: http://www. nrhmtn.gov.in/ntn.html. [Last accessed on 2014 Jun 05].

54. National Programme for Prevention and Control of Cancer, Diabetes, Cardiovascular Diseases and Stroke (NPCDCS). Operational Guidelines. Directorate General of Health Services, Ministry of Health and Family Welfare. Government of India. Available from: http://www.health.bih.nic.in/Docs/Guidelines/ Guidelines-NPCDCS.pdf. [Last accessed on 2014 Jun 05]. 